\title{
Effects of osmolality, morphology perturbations and intracellular nucleotide content during the movement of sea bass (Dicentrarchus labrax) spermatozoa
}

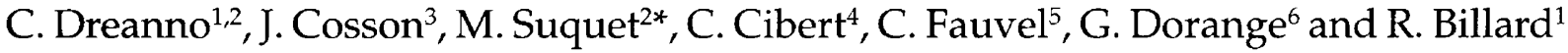 \\ ${ }^{1}$ MNHN, Laboratoire d'Ichtyologie, 43 rue Cuvier, 75231 Paris, France; 2 IFREMER, Laboratoire de Physiologie des Poissons, BP 70, \\ 29280 Plouzané, France; ${ }^{3}$ CNRS, Laboratoire de Biologie Cellulaire, URA 671, 06230 Villefranche sur mer, France; ${ }^{4}$ Institut Jacques \\ Monod, 4 place Jussieu, 75252 Paris, France; IFREMER, Chemin de Maguelone, 34250 Palavas-les-Flots, France; and ${ }^{6} U B O$, Unité de \\ Culture Cellulaire, 29200 Brest, France
}

\begin{abstract}
Sea bass spermatozoa are maintained immotile in the seminal fluid, but initiate swimming for $45 \mathrm{~s}$ at $20^{\circ} \mathrm{C}$, immediately after dispersion in a hyperosmotic medium $\left(1100 \mathrm{mOsm} \mathrm{kg}^{-1}\right)$. The duration of this motile period could be extended by a reduction of the amplitude of the hyperosmotic shock. Five seconds after the initiation of motility, $94.4 \pm 1.8 \%$ of spermatozoa were motile with a swimming velocity of $141.8 \pm 1.2 \mu_{\mathrm{m} \mathrm{s}}{ }^{-1}$, a flagellar beat frequency of $60 \mathrm{~Hz}$ and a symmetric type of flagellar swimming, resulting in linear tracks. Velocity, flagellar beat frequency, percentage of motile cells and trajectory diameter decreased concomitantly throughout the swimming phase. After $30 \mathrm{~s}$ of motility, the flagellar beat became asymmetric, leading to circular trajectories. $\mathrm{Ca}^{2+}$ modulated the swimming pattern of demembranated spermatozoa, suggesting that the asymmetric waves produced by intact spermatozoa after $30 \mathrm{~s}$ of motility were induced by an accumulation of intracellular $\mathrm{Ca}^{2+}$. Moreover, increased ionic strength in the reactivation medium induced a dampening of waves in the distal portion of the flagellum and, at high values, resulted in an arrest of wave generation in demembranated spermatozoa. In non-demembranated cells, the intracellular ATP concentration fell immediately after transfer to sea water. In contrast, the AMP content increased during the same period, while the ADP content increased slightly. In addition, several morphological changes affected the mitochondria, chromatin and midpiece. These results indicate that the short swimming period of sea bass spermatozoa is controlled by energetic and cytoplasmic ionic conditions and that it is limited by osmotic stress, which induces marked changes in cell morphology.
\end{abstract}

\section{Introduction}

In externally fertilizing teleost species, spermatozoa initiate their motility through contact with the external environment when spawning occurs (Morisawa, 1994). The initiation process depends on differences in the environment of the spermatozoa between the reproductive organ and the spawning ground. The mechanism of sperm activation has been studied extensively in salmonid and freshwater species. Many physical and chemical factors, such as osmotic shock, $\mathrm{pH}$ and ionic concentration, have been suggested as triggers of sperm motility (Stoss, 1983; Morisawa, 1994). In rainbow trout (Oncorhynchus mykiss), sperm motility is activated by simple dilution, which leads to a decrease in extracellular $\mathrm{K}^{+}$ (Schlenck and Kahmann, 1938; Morisawa and Suzuki, 1980)

*Correspondence.

Received 22 June 1998 or by addition of divalent cations (Baynes et al., 1981; Billard and Cosson, 1992; Boitano and Omoto, 1992). The initiation of the progressive movement is immediately followed by entry of $\mathrm{Ca}^{2+}$ (Cosson et al., 1989; Boitano and Omoto, 1992) with a consequent increase in intracellular cAMP, which triggers motility by activation of a cAMP-dependent protein kinase (Morisawa and Morisawa, 1990). Nevertheless, the mechanisms regulating sperm motility are not fully understood in fish. Energetic metabolism is considered to be a major factor limiting the duration of sperm motility. In carp (Cyprinus carpio), as well as in trout, the decrease of flagellar beat frequency, velocity and duration of movement have been related to a progressive depletion of the intracellular ATP stores during sperm motion (Christen et al., 1987; Robitaille et al., 1987; Perchec et al., 1995). During the motile period, mitochondrial oxidative phosphorylation does not compensate for the rate of ATP hydrolysis by dynein ATPases (Christen et al., 1987; Perchec et al., 1995). ATP stores 
accumulated before ejaculation are the main energy source sustaining sperm swimming. Nevertheless, the loss of movement may also be associated with other mechanisms because the flagellar beat frequency remains high and the intracellular ATP is not entirely exhausted immediately before total arrest of sperm movement. Osmotic damage affecting cellular structure may result in a limitation of the duration of movement. After exposure to fresh water, the structure of trout spermatozoa is markedly altered. The plasma membrane becomes swollen and disrupted, while the middle piece also becomes disorganized (Billard, 1978). Nevertheless, the short duration of trout sperm motility cannot be attributed entirely to hypo-osmotic shock or to the alteration of membrane structure that occurs within a few minutes (Billard, 1978). In carp, swelling of the sperm head and a progressive but reversible coiling of the flagellum is observed after short-term exposure to fresh water. However, mitochondria are able to synthesize ATP (Perchec et al., 1996).

In trout, $\mathrm{Ca}^{2+}$ modulates the trajectory of spermatozoa by induction of an asymmetric beating (Cosson et al., 1989; Boitano and Omoto, 1992). Intracellular $\mathrm{Ca}^{2+}$ increases during the motility phase, inducing circular swimming patterns (Cosson et al., 1989) and $\mathrm{Ca}^{2+}$ has a direct effect on axonemal movement. In sea urchins (Tripneustes gratilla), $\mathrm{Ca}^{2+}$ modulates the swimming pattern of demembranated spermatozoa, in particular on the asymmetry of the flagellar beat (Gibbons and Gibbons, 1980). Boitano and Omoto (1992) suggested that $\mathrm{Ca}^{2+}$ could act by altering the phosphorylation state of axonemal proteins of trout spermatozoa. In puffers (Takifugu niphobles) and flounders (Kareius bicoloratus), the rise of intracellular $\mathrm{Ca}^{2+}$ could act as a signal triggering the initiation of sperm motility (Oda and Morisawa, 1993).

Few characteristics of the spermatozoa of sea bass (Dicentrarchus labrax) have been reported. The high sperm concentration $\left(1-4 \times 10^{10}\right.$ spermatozoa $\mathrm{ml}^{-1}$; Villani and Catena, 1991), the spermatocrit (ratio of the volume of sperm pellet to the total sperm volume; 65-90\%; Zohar et al., 1984) and the gonado-somatic index (4\%; Barnabé, 1976) all indicate a great spermatogenetic production capacity in this species relative to other teleost fishes (Suquet et al., 1994). The osmolality of the seminal fluid is approximately $400 \mathrm{mOsm} \mathrm{kg}^{-1}$ (Villani and Catena, 1991). The motility of spermatozoa is triggered immediately upon dilution in sea water. Nevertheless, the salinity of the activating medium influences the duration of sperm swimming (Billard, 1984). During the reproduction season, an ageing phenomenon also affects sperm quality, which is expressed in terms of motility (movement duration and percentage of motile cells), fertilization and short-term storage capacities (Billard et al., 1977; Dreanno et al., in press).

The aims of the present work are to describe the swimming behaviour of sea bass spermatozoa during the short motile period and to study the regulating factors that may shorten its duration. Changes in motility parameters were investigated relative to intracellular energy content and sperm morphology. The roles of $\mathrm{Ca}^{2+}$ and ionic strength during the regulation of swimming phase were also investigated.

\section{Materials and Methods}

\section{Broodstock management and sperm sampling}

Broodstocks were composed of 3-5-year-old sea bass, weighing from 1.5 to $4.0 \mathrm{~kg}$. Groups (two males and three females) were kept in $12 \mathrm{~m}^{3}$ concrete tanks. Stocking density was $10 \mathrm{~kg} \mathrm{~m}^{-3}$. The flow rate of sea water was adjusted to $3 \mathrm{~m}^{3} \mathrm{~h}^{-1}$. Each day, animals were fed ad libitum on frozen trash fish and dry pellets. Stocks were submitted to natural or shifted cycles of temperature $\left(13-22^{\circ} \mathrm{C}\right)$ and photoperiod (light:dark, from $8 \mathrm{~h}: 16 \mathrm{~h}$ to $16 \mathrm{~h}: 8 \mathrm{~h}$ ).

Before sperm collection, urine was carefully discarded by checking colour and viscosity changes. The genital area was then dried. Semen was collected by gentle pressure on the testis and sperm ducts through the abdominal wall. Spermatozoa were collected in syringes, stored at $4^{\circ} \mathrm{C}$ and used within $3 \mathrm{~h}$. The percentage of motile spermatozoa was quickly determined as described below and only spermatozoa presenting a high initial motility $(>90 \% 10 \mathrm{~s}$ after activation) were used in these experiments.

All the observations were made at room temperature $\left(18-20^{\circ} \mathrm{C}\right)$.

\section{Motility measurement of intact and demembranated spermatozoa}

Sperm motility was observed using a dark field microscope (Olympus ${ }^{(1)}$ BH-L $\times 10$ ) connected to a camcorder (Canovision ${ }^{\circledast}$ EX1 Hi, Canon). Spermatozoa were visualized on a video monitor (Panasonic ${ }^{\circledR}$ BT-M1420PY) at a final magnification of $\times 750$. Motility measurements were carried out according to Dreanno et al. (1997). Briefly, spermatozoa were activated using a two-step procedure. First, semen was diluted 1:24 in immobilizing medium (IM) composed of 53 mmol NaCl l-1, $1.1 \mathrm{mmol} \mathrm{KCl} \mathrm{l}^{-1}, 4.5 \mathrm{mmol} \mathrm{MgCl}_{2} \mathrm{l}^{-1}, 2.0$ mmol CaCl $\mathrm{l}^{-1}, 0.3 \mathrm{mmol}$ glucose $\mathrm{l}^{-1}, 8 \mathrm{~g} \mathrm{BSA} \mathrm{l}^{-1}, 15 \mathrm{mmol}$ Tris- $\mathrm{HCl} \mathrm{l} \mathrm{l}^{-1}$ adjusted to $\mathrm{pH} 8.2$; osmolality $150 \mathrm{mOsm} \mathrm{kg}{ }^{-1}$. Second, cells were diluted 1:24 in activating medium (AM) composed of natural (osmolality 1100 mOsm kg${ }^{-1}$; AM1100) or diluted sea water in distilled water, $\left(630 \mathrm{mOsm} \mathrm{kg}{ }^{-1}\right.$; AM630), $8 \mathrm{~g} \mathrm{BSA} \mathrm{l}^{-1}, 15 \mathrm{mmol}$ Tris- $\mathrm{HCl}{ }^{-1}$ adjusted to $\mathrm{pH} 8.2$. The osmolality of the media was controlled using a Roebling ${ }^{\oplus}$ micro-osmometer. The percentage of motile cells (spermatozoa with progressive forward motility) was determined by measurement of the number of tracks using successive video still frames. Swimming velocity was determined using the Computer Assisted Sperm Analysis (CASA) system (Modcell) developed by Schoëvaërt et al. (1988). The software parameters were adjusted for sea bass sperm characteristics. The beat frequency of the flagellum was assessed according to Cosson et al. (1985).

Images of native and permeabilized flagella of moving spermatozoa were obtained using the method described by Cosson et al. (1997). Briefly, spermatozoa were observed with an Olympus ${ }^{\circledR}$ BH2 microscope combined with an Olympus ${ }^{\circledR}$ Dark Field oil condenser DWC 1.4-1.2. Video records were made with a Panasonic ${ }^{\oplus}$ WV-F15ES-VHS video-camera (frame rate: $50 \mathrm{~Hz}$ ), connected to a Hamamatsu ${ }^{\mathbb{E}}$ video image Downloaded from Bioscientifica.com at 04/26/2023 12:11:57PM 
processor (DVS 3000) and a Panasonic ${ }^{\circledR}$ AG 7330 S-VHS video-recorder synchronized to the stroboscopic illumination with a fibre optic 'video-sync' module number 9630 (Chadwick-Helmuth $^{\circledast}$ ). The stroboscopic flash illumination was set between 150 and $800 \mathrm{~Hz}$, depending on the time resolution needed. During the recording process, the microscope stage was hand translated slowly, allowing the visualization of multiple, well-defined, successive images of individual moving spermatozoa within each video frame. Direct photographs of sperm cells were also obtained using an Olympus ${ }^{\circledast} \mathrm{OM} 2$ camera.

The local curvature of flagella was analysed according to Cosson et al. (1997). For measurement of the shear angle along the flagellum, the angle for each partition either relative to the head axis or to an arbitrary and constant reference axis was plotted against its curvilinear abscissa. The flagellar skeletons were divided into 150 partitions. The origin of each partition was considered as the curvilinear origin of a 20 pixel segment. The first derivative of the regression line was calculated.

The reactivation of flagellar movement was adapted from the procedure of extraction and reactivation described in rainbow trout spermatozoa by Cosson et al. (1995). Spermatozoa were first diluted in IM (dilution: 1:3) to prevent aggregation, and then in AM (dilution: 1:10) to assess the motility of demembranated spermatozoa. A sample $(20 \mu \mathrm{l})$ of this diluted sperm suspension was added to $180 \mu \mathrm{l}$ demembranation medium (DM) containing $100 \mathrm{mmol}$ potassium acetate ${ }^{-1}, 1 \mathrm{mmol}$ dithiothreitol (DTT) $1^{-1}, 0.5 \mathrm{mmol} \mathrm{CaCl}_{2} \mathrm{l}^{-1}$, $0.5 \mathrm{mmol} \mathrm{EDTA}^{-1}, 20 \mathrm{mmol}$ Tris- $\mathrm{HCl} \mathrm{l}^{-1}, 0.04 \%(\mathrm{w} / \mathrm{v})$ Triton$\mathrm{X} 100$ adjusted to $\mathrm{pH} 8.2$ at $4^{\circ} \mathrm{C}$, for membrane permeabilization. After $30 \mathrm{~s}$ incubation, $2 \mu \mathrm{l}$ of this suspension was mixed with $18 \mu \mathrm{l}$ of reactivation medium (RM) composed of potassium acetate at various concentrations (from 25 to $\left.500 \mathrm{mmol} \mathrm{l}^{-1}\right), 1 \mathrm{mmol}$ DTT l-1, $1 \mathrm{mmol} \mathrm{MgSO}_{4} \mathrm{l}^{-1}, 1 \mathrm{mmol}$ ATP $~^{-1}$ (vanadate-free from Boehringer, Meylan; stock solution neutralized at $\mathrm{pH} \mathrm{7.0),1} \mathrm{g} \mathrm{BSA} \mathrm{l}^{-1}, 20 \mathrm{mmol}^{\mathrm{Tris}}-\mathrm{HCl}^{-1}$, pH 8.2 and, when indicated, 2 mmol EGTA ${ }^{-1}$.

The concentration of free $\mathrm{Ca}^{2+}$ in the different solutions was calculated using a shared software called 'free $\mathrm{Ca}$ program', which takes into account the total ATP, EDTA, $\mathrm{H}^{+}$, $\mathrm{K}^{+}$, EGTA, $\mathrm{Mg}^{2+}$ and $\mathrm{Ca}^{2+}$ concentrations present in these media using affinity constants published by Brokaw (1986). Thus, the free $\mathrm{Ca}^{2+}$ concentration present in $\mathrm{DM}$ was estimated as $1.2 \times 10^{-6} \mathrm{~mol} \mathrm{l}^{-1}$. It was $2 \times 10^{-11} \mathrm{~mol} \mathrm{l}^{-1}$ when ATP and $\mathrm{Mg}^{2+}$ were added at $1 \mathrm{mmol} \mathrm{l^{-1 }}$ in RM. The concentration of the ATP-Mg complex was also estimated using the same program and was never $>10 \%$ lower than the total ATP concentration in all the in vitro conditions used in this work when the added $\mathrm{Mg}^{2+}$ concentration was maintained at $1 \mathrm{mmol} \mathrm{l}^{-1}$.

\section{Kinematic measurements of sperm head tracks}

Straight-line velocity (VSL) was defined as the time average velocity of the sperm head along a straight line from its first position to its last position. Curvilinear velocity (VCL) was defined as the time average velocity of the sperm head along its actual trajectory. Velocities were expressed in $\mu \mathrm{m} \mathrm{s}^{-1}$. The linearity index is deduced from the VSL:VCL ratio. Curvature was determined by measuring the diameter of a circle obtained by drawing a line at an equal distance from successive flagellar waves (middle line bisecting the flagellar 'envelope'). The track diameter was measured on the trajectory of the sperm head obtained by accumulation of successive images with the Hamamatsu ${ }^{\circledR}$ video image processor. The wavelength was defined as twice the length of the segment between the two inflexion points adjacent to a bend. The wave amplitude was defined as the height determined by the wave axis that was approximately perpendicular to the average path. The flagellar beat frequency, determined with the stroboscope, was defined as the number of waves that appeared at the base of the head in the proximal part of the flagellum during $1 \mathrm{~s}$. The average distance $(D)$ covered by spermatozoa during the motility period was calculated from the integral of the velocity versus time, where $v$ is the velocity and $t$ represents the time after activation:

$$
D=\int_{t_{0}}^{t}\left(-\frac{v_{0}}{t_{0}}\left(t+v_{0}\right)\right) \mathrm{d} t
$$

\section{Intracellular adenylate nucleotide concentration measurements}

The cellular content of spermatozoa at various times after activation was extracted by $15 \%(\mathrm{w} / \mathrm{v})$ trichloroacetic acid (TCA) at $4^{\circ} \mathrm{C}$. After a $10 \mathrm{~min}$ incubation, homogenates were centrifuged at $1600 \mathrm{~g}$ for $15 \mathrm{~min}$ at $4^{\circ} \mathrm{C}$. The supernatant was neutralized by addition of amine-freon $\left(0.5 \mathrm{~mol} \mathrm{l}^{-1}\right)$ and stored at $-20^{\circ} \mathrm{C}$ until HPLC analysis. HPLC nucleotide analysis was performed as described by Suquet et al. (1998). The adenylate energy charge (AEC) proposed by Atkinson (1968) is defined as:

$$
\mathrm{AEC}=\left[\frac{[\mathrm{ADP}]+2[\mathrm{ATP}]}{[\mathrm{AMP}]+[\mathrm{ADP}]+[\mathrm{ATP}]}\right] \times \frac{1}{2} \times 100
$$

Sperm concentration was determined by spectrophotometric light absorption at $260 \mathrm{~nm}$ after dilution in distilled water (1:250) (C. Fauvel, unpublished).

\section{Ultrastructure of the spermatozoon}

Sperm samples were fixed either immediately after collection or after $40 \mathrm{~s}$ in AM. Aliquots were fixed and embedded according to the methods of Suquet $e$ al al (1998). The osmolality of fixative and washing buffers was adjusted to the value of the osmolality of the incubation medium by addition of $\mathrm{NaCl}$. Ultrathin sections were contrasted by alcoholic uranyl acetate and lead citrate. Sections were examined with a JEOL'TEM ${ }^{\otimes} 100 C^{\prime}$ electron microscope.

\section{Statistical analysis}

Data are expressed as means \pm SEM. Energy charge values were subjected to angular transformation. Data were 
compared using a two-way analysis of variance. When differences were significant $(P<0.05)$, a Tukey a posteriori test was used for comparison. After Neperian log transformation of time after activation and angular transformation of velocity and flagellar beat frequency of motile spermatozoa, changes in these two last parameters with time were modelled using a linear regression (Statistica ${ }^{\circledR}$ Software).

\section{Results}

\section{Movements of live spermatozoa}

Direct microscopic observations of spermatozoa in their seminal fluid before any dilution showed that they were not spontaneously motile. After transfer into activating solution (AM1100), the percentage of motile cells remained high during the first $10 \mathrm{~s}$ (Fig. 1a) and then started to decrease slowly. From 10 to $30 \mathrm{~s}$ after activation, the percentage of motile cells dropped significantly. At $35 \mathrm{~s}$ after activation, an increasing number of spermatozoa showed very low translational motility, although their flagellum continued beating for a few seconds at low frequencies. The heads of these spermatozoa showed lateral movements of larger amplitude. Within a few seconds (40-45 s after activation), all sperm cells stopped swimming with the whole flagellum immobilized in a slightly curved shape. When spermatozoa were diluted in AM630, changes in the percentage of motile cells were similar to those observed in AM1100. However, the total duration of movement was longer, reaching up to 2 min. At the end of the swimming period, spermatozoa diluted in AM630 showed only shivering and untranslational movements. Immediately after activation, the flagellar beat frequency was stable at about $60 \mathrm{~Hz}$ (in AM1100 or AM630; Fig. 1b) for all sperm cells. At $20 \mathrm{~s}$ after activation, the beat frequency dropped suddenly to values of about $20 \mathrm{~Hz}$ for both diluents and kept decreasing until the arrest of all movement. The changes of flagellar beat frequency relative to elapsed time were fitted with a straight line for the period 10-40 s after activation (AM1100: $F=$ $-0.859 t+1.696, r^{2}=0.87$; AM630: $y=-0.824 x+1.704, r^{2}=0.86$; $F$ and $t$ representing flagellar beat frequency and time after activation, respectively) to compare the changes in the parameters of motility induced by dilution in AM1100 or AM630. No significant difference was observed between the slopes obtained from plots of the two diluents. After activation by AM1100, the mean straight line velocity and the curvilinear velocity were $141.9 \pm 8.0 \mu \mathrm{m} \mathrm{s}^{-1}$ and $114.5 \pm 16.2 \mu \mathrm{m} \mathrm{s}^{-1}$, respectively (Fig. 1C). Both velocities dropped significantly at $20 \mathrm{~s}$ after activation (straight line velocity: $63.7 \pm 13.1 \mu \mathrm{m} \mathrm{s}^{-1}$, curvilinear velocity: $102.8 \pm 8.1 \mu \mathrm{m} \mathrm{s}^{-1}$ ) and then decreased as a function of time. After log transformation of velocity, these changes with time were fitted to a straight line (straight line velocity, AM1100: $V=-2.766 t+159.413, r^{2}=0.95$; AM630: $V=$ $-2.726 t+158.201, r^{2}=0.95$; where $V$ and $t$ represent the velocity and the time after activation, respectively). Slopes recorded after dilution in AM1100 or AM630 were not significantly different. The average distances covered by spermatozoa during the $40 \mathrm{~s}$ swimming period in AM1100 and AM630 were 2.3 and $2.0 \mathrm{~mm}$, respectively. The distance covered was calculated from 5 to $40 \mathrm{~s}$ after activation, since the low flagellar beat frequency at later times did not allow translational movement.

When observed immediately upon dilution, all spermatozoa swam vigorously along quasi-straight trajectories during the first $10 \mathrm{~s}$ (trajectory diameter: $187.3 \pm 4.6 \mu \mathrm{m}$ ). After $20 \mathrm{~s}$, the trajectories of spermatozoa described circles the diameter of which decreased regularly to values of 20-30 $\mu \mathrm{m}$ just before the arrest of flagellar beating (Fig. 2). As a consequence, the linearity index, defined as the ratio between the straight line velocity and the curvilinear velocity, significantly decreased between 5 and $30 \mathrm{~s}$ after activation (Fig. 1d). The increase in curvature of the tracks is known to be a consequence of the degree of wave asymmetry in sea urchin spermatozoa (Gibbons and Gibbons, 1980). Successive images of the wave pattern developed by flagella after various periods of time elapsed after activation are shown (Fig. 3). In each series, the angular direction (shear angle) of the flagellum was quantified and plotted as a function of the distance from the head at successive time points along their beat cycle. From $11 \mathrm{~s}$ after activation (Fig. 3a), flagella exhibit very symmetrical patterns. At later time points (24 s in Fig. 3b), a higher asymmetry appears in the flagellar beat pattern. During the latest period (just before arrest), flagella become highly asymmetric (31 s in Fig. 3c).

\section{Ionic regulation}

Since native spermatozoa are activated by transfer into a hyperosmotic medium, an osmotic shock should lead to readjustment of the internal calcium concentration and ionic strength. Demembranated-ATP reactivated spermatozoa were used as models to investigate the role of $\mathrm{Ca}^{2+}$ and ionic strength by varying the $\mathrm{Ca}^{2+}$ and potassium acetate concentrations on the axonemes. With increasing $\mathrm{Ca}^{2+}$ content in the RM, the diameter of sperm trajectories decreased (Fig. 4a and Fig. 5) as a result of an asymmetry of flagellar beating, as observed at high $\mathrm{Ca}^{2+}$ concentrations and low ionic strength (Fig. 6a). An increase in ionic strength also leads to a dampening of distal waves (Fig. 7). $\mathrm{Ca}^{2+}$ also regulated the twist of the flagellum. At high $\mathrm{Ca}^{2+}$ concentrations, spermatozoa circled according to a planar trajectory, coplanar with their beating plane (Fig. 6a-d). In contrast, at low $\mathrm{Ca}^{2+}$ concentrations, spermatozoa described much more linear tracks. However, their beating plane rotated as spermatozoa were seen alternately from the top and side (Fig. 6e-g, lower panels). In this latter condition, the average rotation frequency was around $5 \mathrm{~Hz}$. The flagellar beat frequency was only slightly affected by the potassium acetate concentration, except at high values (>300 $\mathrm{mmol} \mathrm{l}^{-1}$ ) (Fig. 4b). The curvature increased markedly with potassium acetate at low $\mathrm{Ca}^{2+}$ concentration (Fig. 4c). The wave amplitude decreased with potassium acetate concentration at low $\mathrm{Ca}^{2+}$ concentration $\left(2 \times 10^{-11} \mathrm{mmol} \mathrm{l}^{-1}\right)$ (Fig. $\left.4 \mathrm{~d}\right)$, but increased with the potassium acetate concentration at high $\mathrm{Ca}^{2+}$ concentration $\left(1.4 \times 10^{-6} \mathrm{mmol} \mathrm{l}^{-1}\right)$. In contrast, the wavelength increased significantly from $12-17$ to $30-35 \mu \mathrm{m}$ with increasing potassium acetate concentration, whereas $\mathrm{Ca}^{2+}$ concentration did not modify this pattern (Fig. 4e). Similar effects of ionic 
(a)

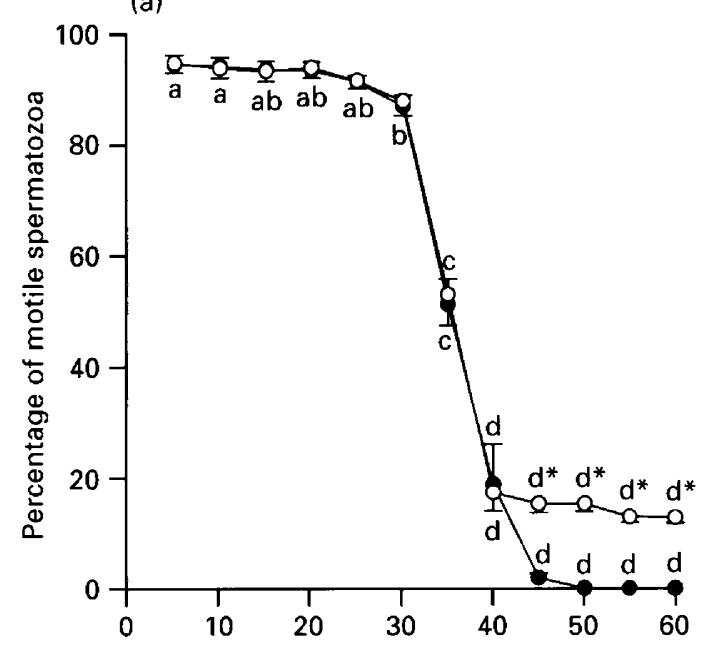

(c)

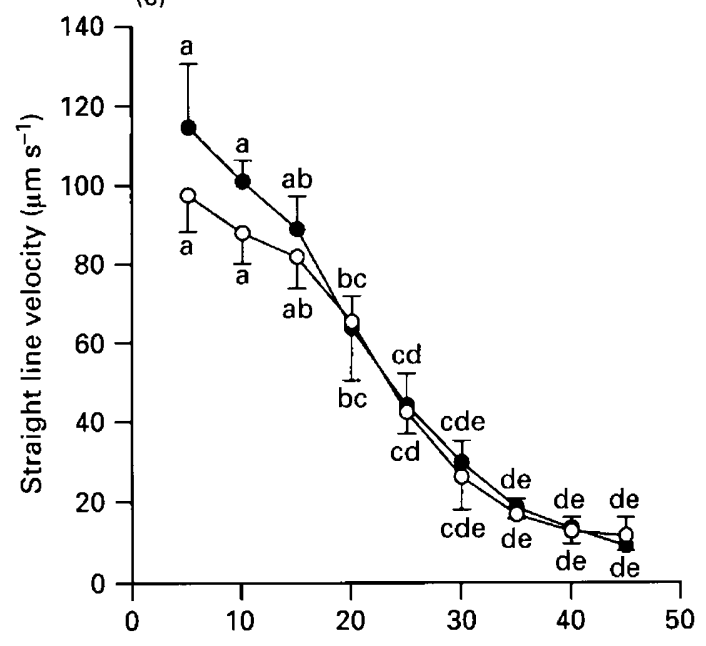

(b)

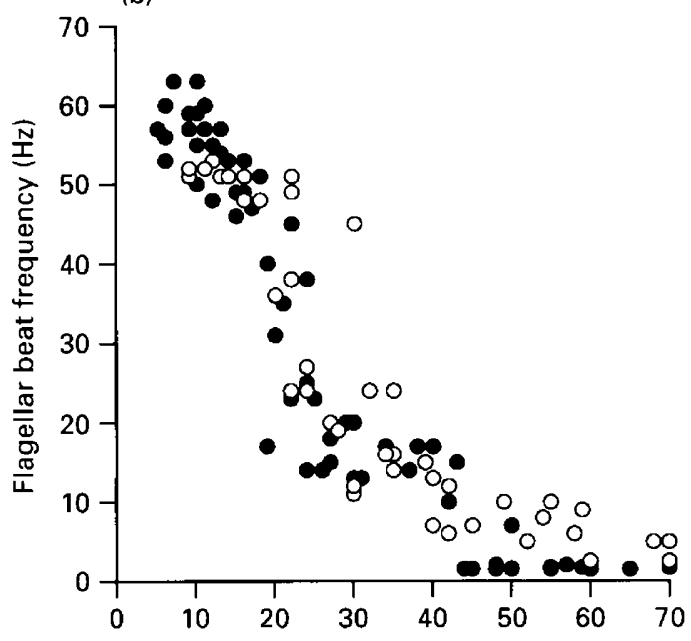

(d)

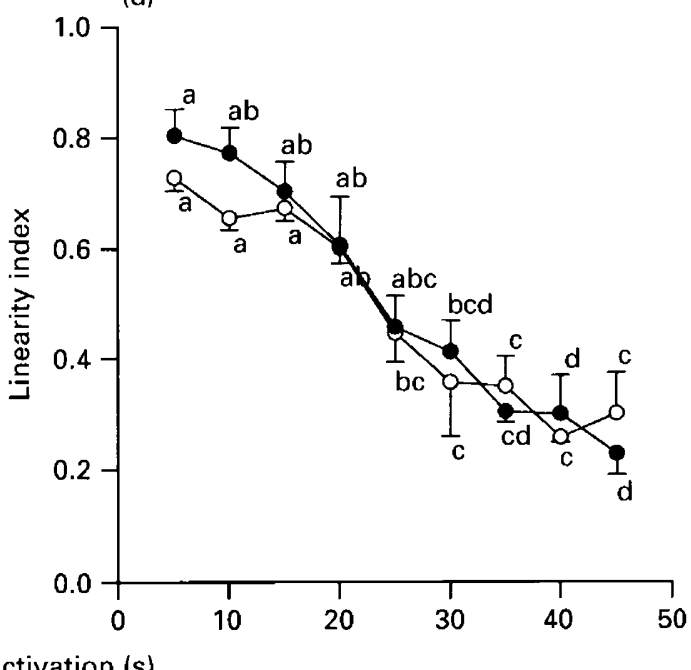

Fig. 1. Changes in motility parameters versus time in sea bass spermatozoa after dilution in AM1100 (O) and AM630 (O). (a) Percentage of motile spermatozoa, (b) flagellar beat frequency, (c) straight line velocity, and (d) linearity index, as defined by the ratio of straight line velocity to curvilinear velocity. Significantly different values versus time are indicated by different superscripts for the same activating medium. Asterisks indicate significantly different values at various times after activation between spermatozoa diluted in AM1100 and in AM630 $(P<0.05)$.

strength were observed with other ions (for example, $\mathrm{Na}^{+}, \mathrm{Cl}^{-}$; data not shown) in the same concentration ranges as potassium acetate, but sperm motility was less stable in these media. The effect of $\mathrm{Ca}^{2+}$ on the asymmetry of beating was also observed when modifying the $\mathrm{Ca}^{2+}$ concentration of artificial sea water, but this is not documented in detail in this paper.

\section{Energetic regulation}

After dilution in AM1100, the initial intracellular ATP concentration dropped significantly from $11.49 \pm 1.05 \mathrm{nmol}$ per $10^{8}$ spermatozoa to $3.04 \pm 0.95 \mathrm{nmol}$ per $10^{8}$ spermatozoa at $10 \mathrm{~s}$ after activation (Fig. 8a). In contrast, the ADP concentration increased from $1.08 \pm 0.48 \mathrm{nmol}$ per $10^{8}$ spermatozoa to $4.03 \pm 0.76 \mathrm{nmol}$ per $10^{8}$ spermatozoa at $20 \mathrm{~s}$ after activation and remained stable. The AMP concentration increased significantly from $0.57 \pm 0.10 \mathrm{nmol}$ per $10^{8}$ spermatozoa to $8.03 \pm 0.59 \mathrm{nmol}$ per $10^{8}$ spermatozoa at $10 \mathrm{~s}$ after activation. The adenylate energy charge decreased suddenly from $0.92 \pm 0.02$ to $0.31 \pm 0.05$ at $10 \mathrm{~s}$ after activation and then decreased gradually during the swimming period (Fig. 8b).

\section{Ultrastructure of sea bass spermatozoa}

The general morphology of sea bass spermatozoa, as examined by transmission electron microscopy, is simple (Fig. 9a). The head of the unactivated spermatozoon is 


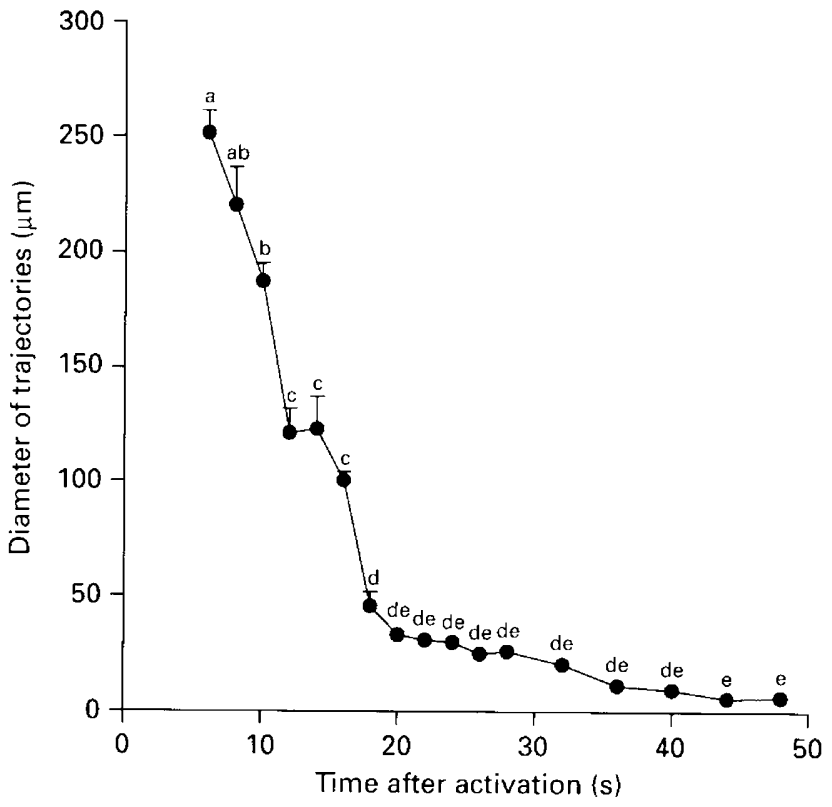

Fig. 2. Change in the diameter of sea bass sperm trajectories during the motile phase. Significantly different values of diameters versus time are indicated by different superscripts $(P<0.05)$.

round, measuring $1.37 \pm 0.13 \mu \mathrm{m}$ from the anterior to the posterior part. The length and width of the nucleus are $1.29 \pm$ $0.20 \mu \mathrm{m}$ and $0.87 \pm 0.14 \mu \mathrm{m}$, respectively. The spermatozoon is devoid of any acrosome (Fig. 9a,b). At the apical part, the nuclear envelope is detached from the plasma membrane, leading to the formation of a cytoplasmic space (Fig. 9b). The degree of chromatin condensation is low, with many irregular flocculent dense masses. A small depression is present at the posterior part of the nucleus where both centrioles are anchored. The proximal centriole is roughly perpendicular to the distal centriole (Fig. 9g). At the posterior part of the midpiece, 2-4 subspherical mitochondria are arranged in a ring. In the mitochondria, few cristae are present with most of the volume being occupied by intracellular spaces (Fig. 9b). Several small vesicles are present in the middle piece. The posterior narrow part of the middle piece is invaginated and forms a cytoplasmic canal. At that point, the middle piece shows a densification of the membrane (Fig. 9c). The axoneme shows

Fig. 3. Measurement of the shear angle along the flagellum of sea bass spermatozoa at successive times after activation: (a) $11 \mathrm{~s}$, (b) $24 \mathrm{~s}$, and (c) $31 \mathrm{~s}$ after activation. In the top panel, successive positions show the same flagellum; two positions were separated by $3 \mathrm{~ms}$ and were obtained by translation of the microscope stage. In the bottom left panel, the same sperm image obtained without stage translation shows the superimposed beating waves and illustrates the beating envelope. In the bottom right panel, the shear angle is measured on a series of sperm images along the flagellum as a function of the distance from the head. For each position, the head is located on the left hand of each plot at position 0 on the $x$-axis. Positive values correspond to the clockwise direction of the shear angle. Lines of increasing intensity represent successive shear patterns from 1 to 12 . Scale bars represent $20 \mu \mathrm{m}$. (a)

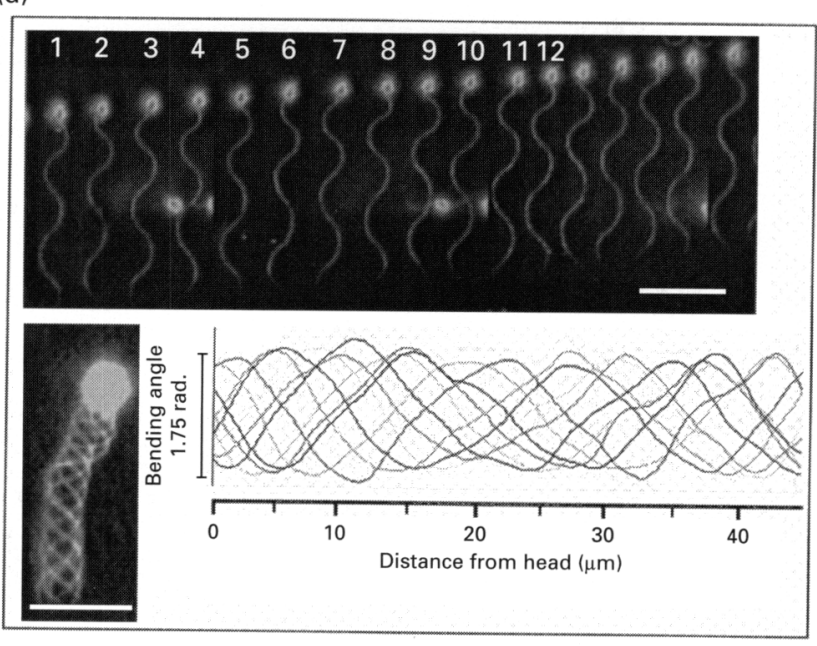

(b)

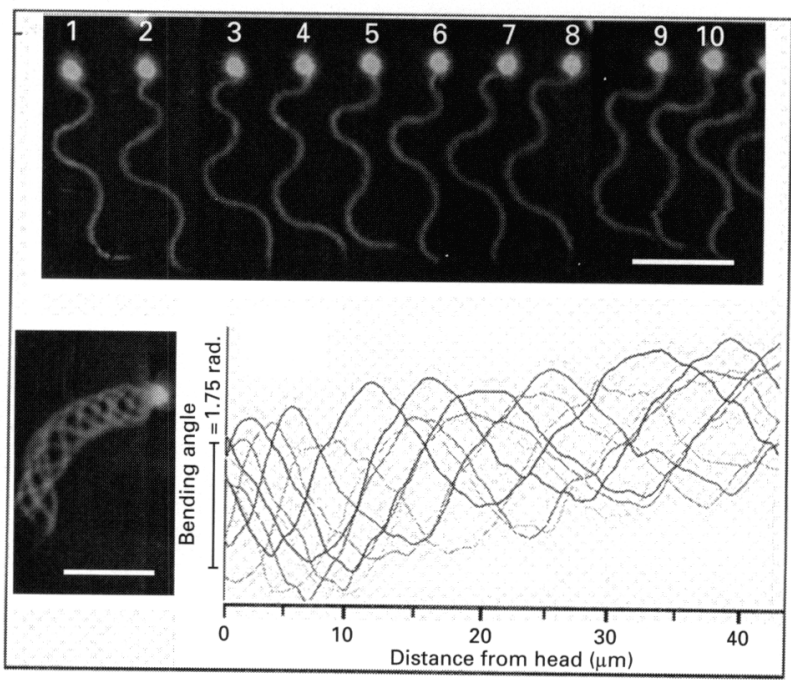

(c)

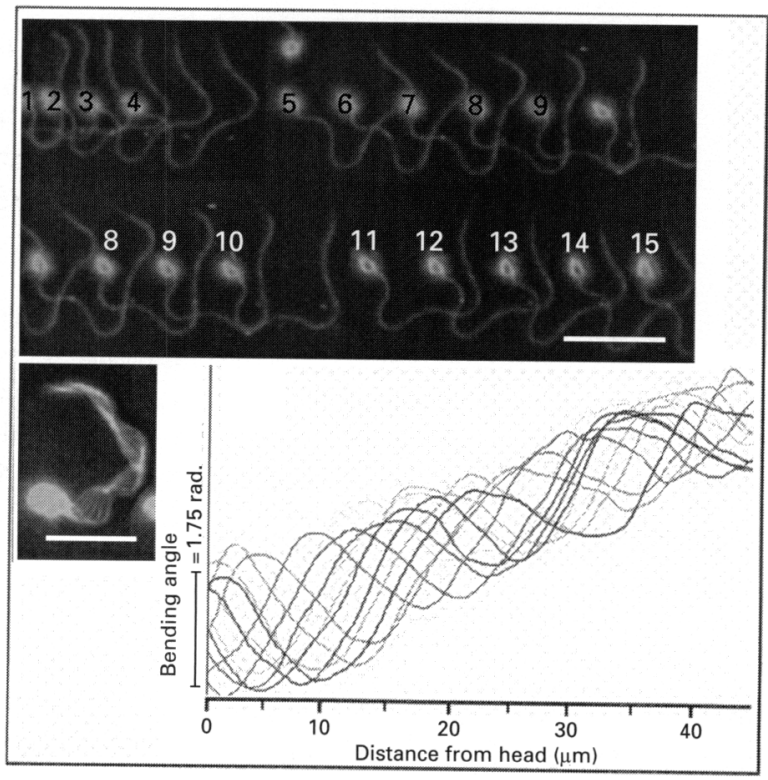


(a)

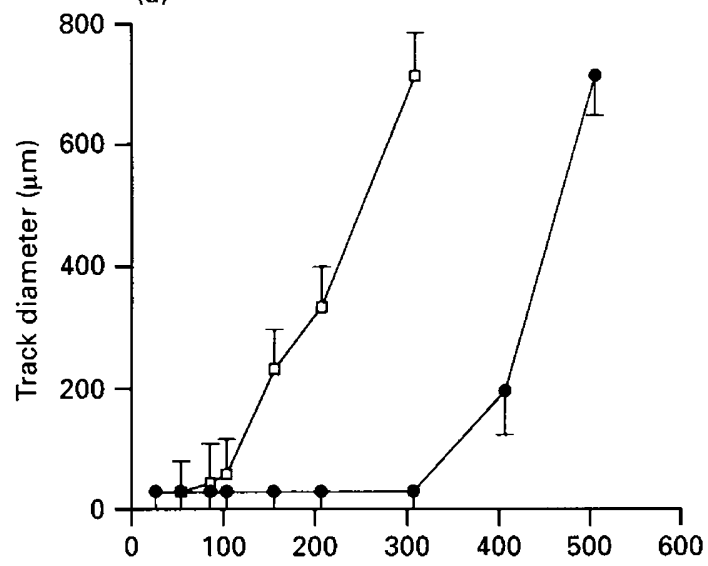

(c)

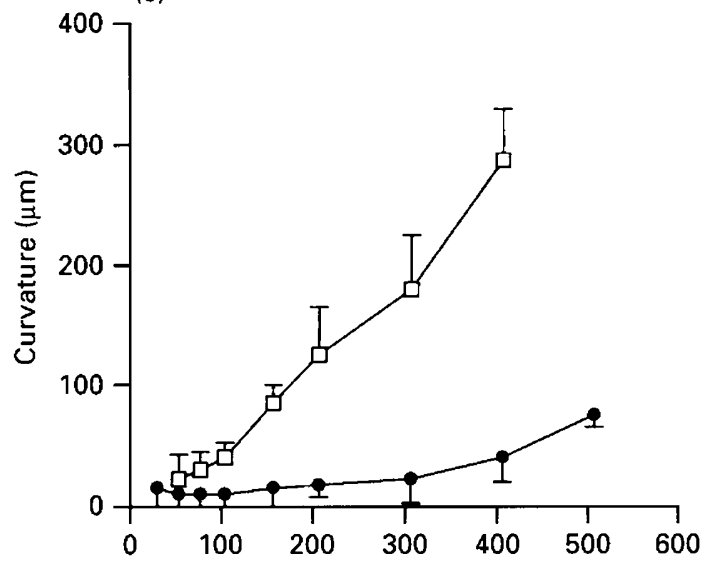

(b)

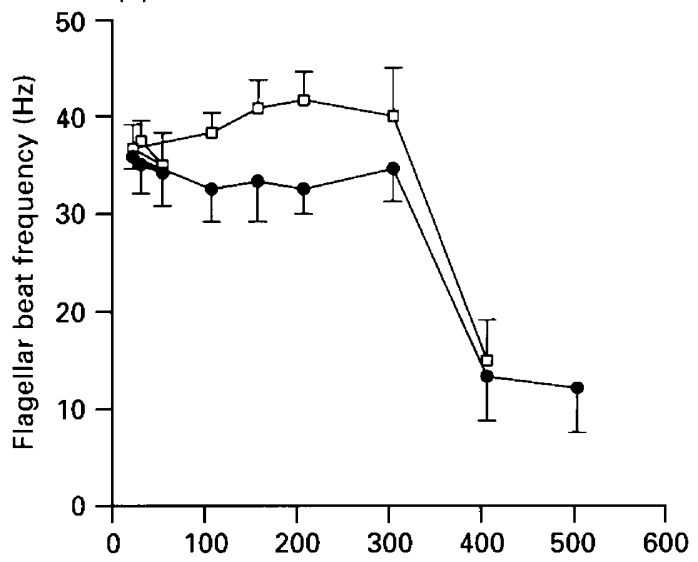

(d)

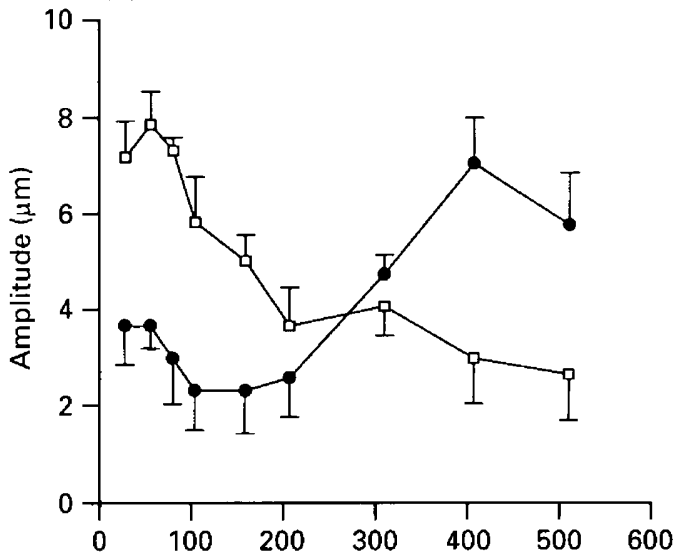

(e)

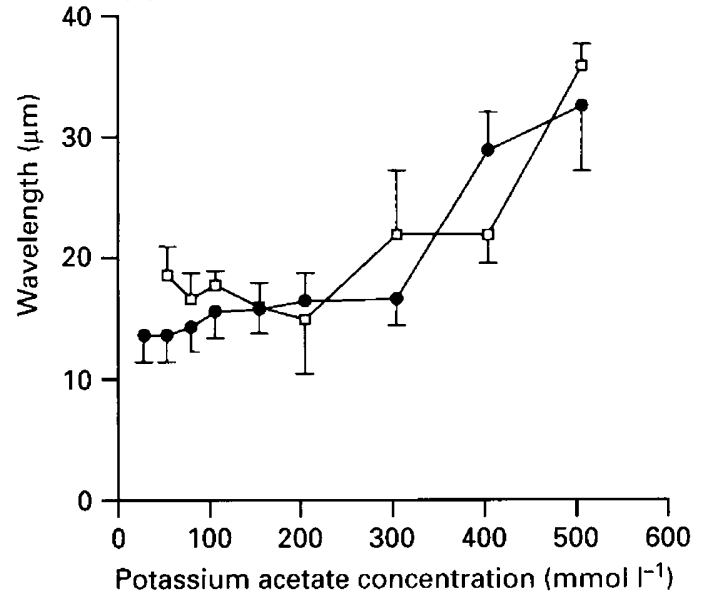

Fig. 4. Effect of potassium acetate concentration in reactivating medium in the presence $(\square)$ or absence ( $\square$ ) of EGTA $\left(2 \mathrm{mmol} \mathrm{l}^{-1}\right)$ on (a) the track diameter, (b) the flagellar beat frequency, (c) the curvature, (d) the wave amplitude, and (e) the wavelength of sea bass spermatozoa.

the classic ' $9+2$ ' pattern (Fig. 9d). In the vicinity of some spermatozoa, structures possibly identified as cellular residues (Fig. 9e) indicate that spermiogenesis stills occurs in the lumen of the lobule after the spermatozoa are released from cysts. At $40 \mathrm{~s}$ after activation, marked changes are observed in the nucleus. The chromatin appears heterogeneous, exhibiting coarse masses narrowly separated by a pale matrix (Fig. 9f-h). A significant swelling of the head was also noted; the maximum diameter was $1.67 \pm 0.13 \mu \mathrm{m}$. The nucleus itself swells, increasing significantly its length and width to 

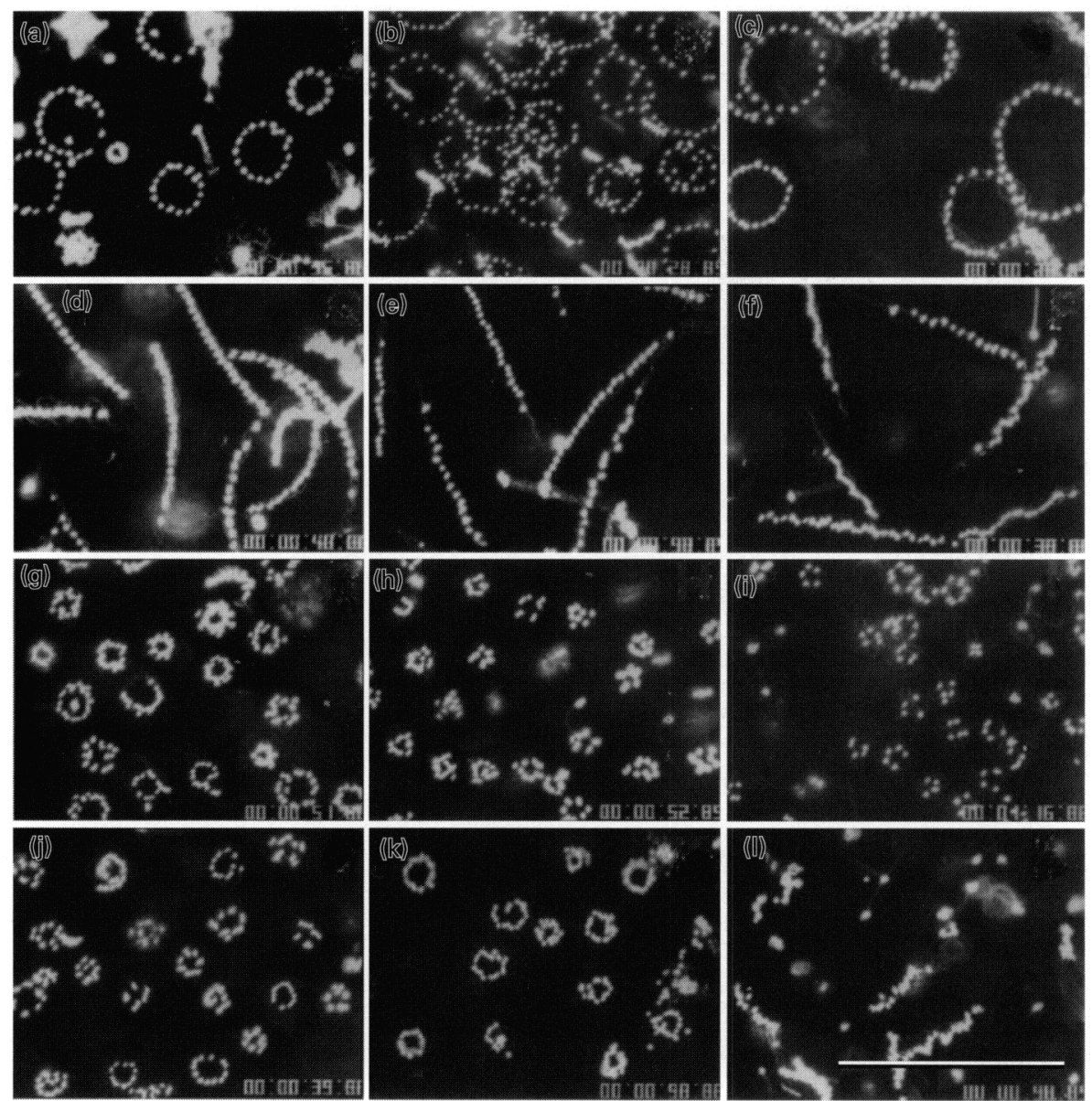

Fig. 5. Video records of swimming demembranated sea bass spermatozoa diluted in reactivating medium relative to the potassium acetate concentration and the presence of EGTA. EGTA ( 2

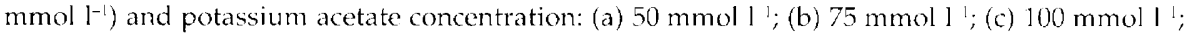
(d) $200 \mathrm{mmol} \mathrm{l}^{1}$; (e) $300 \mathrm{mmol}^{-1}$; (f) $400 \mathrm{mmol}^{1}$ '. No EGTA and potassium acetate concentration:

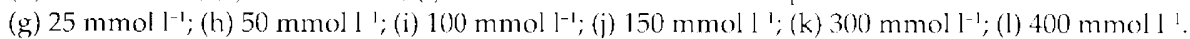
Scale bar represents $50 \mu \mathrm{m}$.

$1.60 \pm 0.11 \mu \mathrm{m}$ and $1.28 \pm 0.17 \mu \mathrm{m}$, respectively. At the apical part of the head, the plasma membrane sticks to the nuclear envelope. Mitochondria are shrunk, with some intracristae spaces greatly enlarged.

\section{Discussion}

The spermatozoa of sea bass are completely quiescent in the seminal plasma and their motility is triggered by an increase of their surrounding osmolality as has been described for other marine fish species (Billard et al., 1993; Oda and Morisawa, 1993; Chauvaud et al., 1995; Cosson ct al., 1997; Lahnsteiner and Patzner, 1998). The swimming pattern upon full activation consists of an initial phase of $20 \mathrm{~s}$ with quasilinear trajectories, followed by a second phase (from 20 to $40 \mathrm{~s}$ after activation) with circular swimming, leading to a cessation of movement owing to a straightening of the flagellum. A high percentage of motile spermatozoa showing a flagellar beat frequency of about $60 \mathrm{H} \%$ and a high velocity characterize the first $20 \mathrm{~s}$ after activation. Bending waves appear and progress along the length of the flagellum with a constant amplitude. These waves are sinusoidal and are similar to those observed in trout spermatozoa (Cosson et al., 1989). The general swimming pattern of sea bass spermatozoa is similar to that reported for carp (Perchec et al., 1995), trout (Cosson et al., 1995), puffer and flounder (Oda and Morisawa, 1993) in terms of the briefness of the motion period, the evolution of the swimming velocity, and the decrease in the flagellar beat frequency, but contrasts slightly with that reported for turbot (Psetta maxima) (Chauvaud et al., 1995) and halibut (Hippoglossus hippoglossus; Billard et al., 1993). In turbot and halibut, the frequency remains high for a longer period after activation and drops abruptly at 40 and $60 \mathrm{~s}$ after activation, respectively. In turbot, a gradual dampening of waves in the distal part of the flagellum was 

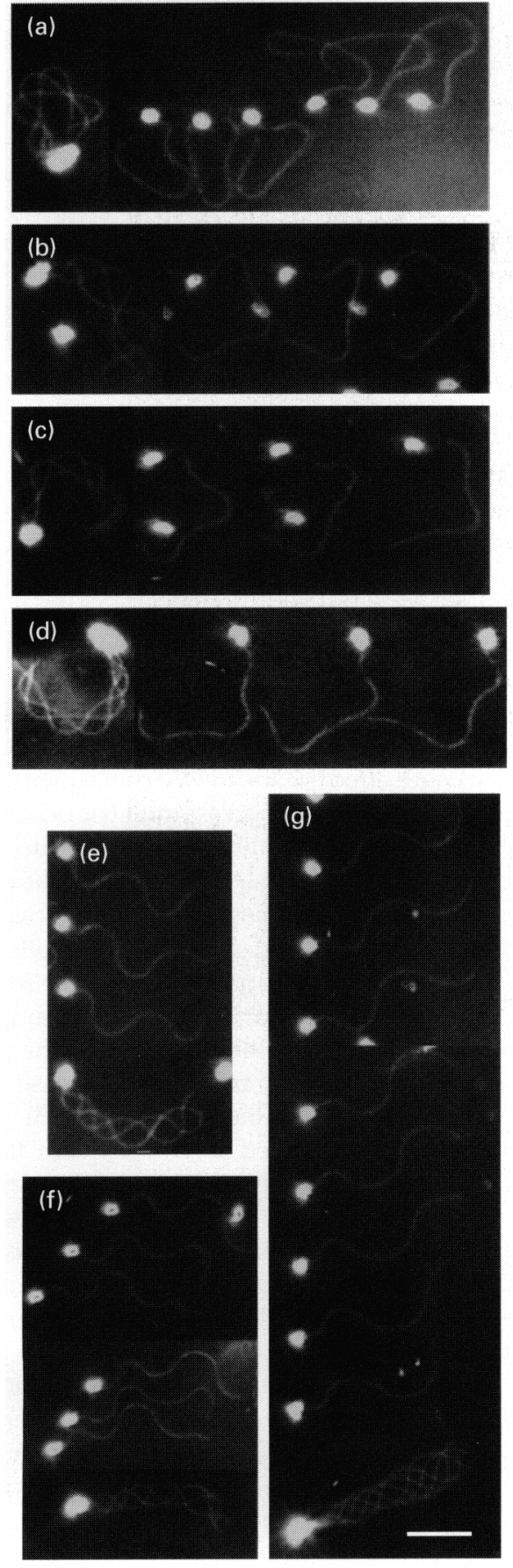

Fig. 6. Video records of swimming demembranated sea bass spermatozoa diluted in reactivating medium relative to the $\mathrm{KCl}$ concentration and the presence of $2 \mathrm{mmol}$ ECTA I'. No EGTA and

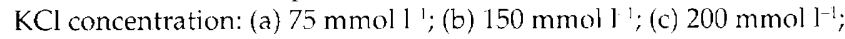
(d) $300 \mathrm{mmol} \mathrm{l^{-1 }}$. EGTA $\left(2 \mathrm{mmol} \mathrm{l}^{-1}\right)$ and $\mathrm{KCl}$ concentration: (e) $75 \mathrm{mmol} \mathrm{l}^{-1}$; (f) $150 \mathrm{mmol} \mathrm{l}^{-1}$; (g) $200 \mathrm{mmol} \mathrm{l}^{-1}$. Scale bar represents $15 \mu \mathrm{m}$.

also observed. The most distal part of the flagellum becomes stiffer in such a way that the whole length of the flagellum appears to be straight at the end of the movement period; however, no change in the symmetry of the beating wave

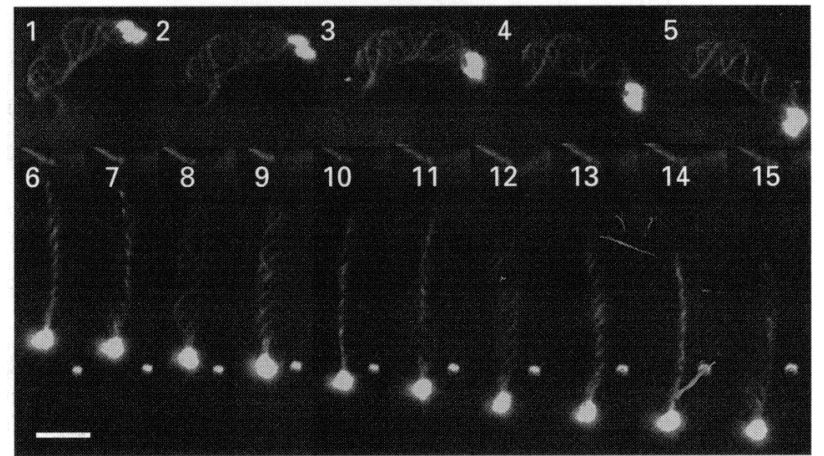

Fig. 7. Video records of swimming demembranated sea bass spermatozoa showing the rotation during asymmetrical swimming (6-15) and the absence of rotation when symmetrical swimming (1-5). Scale bar represents $15 \mu \mathrm{m}$.

was noted during the swimming of spermatozoa (Cosson et al., 1997), which may result from the absence of a $\mathrm{Ca}^{2+}$ effect on spermatozoa in this species.

As has been reported in trout, halibut, turbot and puffer spermatozoa (Billard and Cosson, 1989; Billard et al., 1993; Chauvaud et al., 1995; Oda and Morisawa, 1993), the decrease in flagellar beat frequency of sea bass spermatozoa as a function of time after activation correlates with the decrease in velocity. The duration of motility of sea bass spermatozoa observed in the present study was shorter than that reported by Billard (1984) (3-30 min), Villani and Catena (1991) (5 min) and Sorbera et al. (1996) (3 min) in the same species. These discrepancies may be due to the sperm activation procedure, that is, the method used in the present study included a sperm predilution step in a non-activating medium and a 1:1000 final dilution of spermatozoa for motility assessment. This method, described by Billard and Cosson (1992), prevents undiluted sperm packs from acting as stores that progressively release newly activated cells. Furthermore, the high final dilution improves the accuracy of the assessment of motile cells. In contrast, the motility of sea bass spermatozoa was assessed in previous work after a final dilution of only 1:100, without predilution in immobilizing medium.

As a consequence of the short motility duration and the rapid decrease in velocity versus time, the calculated swimming distance covered by sea bass spermatozoa (average: $2.3 \mathrm{~mm}$ ) was lower than the values reported for trout (2.5-3.0 mm; Cosson et al., 1989), carp (5-6 mm; Perchec et al., 1995) and turbot (12 mm; Chauvaud et al., 1995). Furthermore, the effective distance is even smaller if it is taken into consideration that between 35 and $45 \mathrm{~s}$ after activation, the movement of sea bass spermatozoa is mostly untranslational, as cells are circling. The short distance covered by sea bass spermatozoa and the greater diameter of ova (1.07-1.32 mm; Devauchelle and Coves, 1988) compared with those in turbot should decrease the probability of spermatozoa reaching the micropyle entrance. A larger number of spermatozoa per ovum would be required for the fertilization process to compensate for this. The low capacity of sea bass spermatozoa compared with that of turbot can be partially offset by the high gonado-somatic index (sea bass: 
(a)

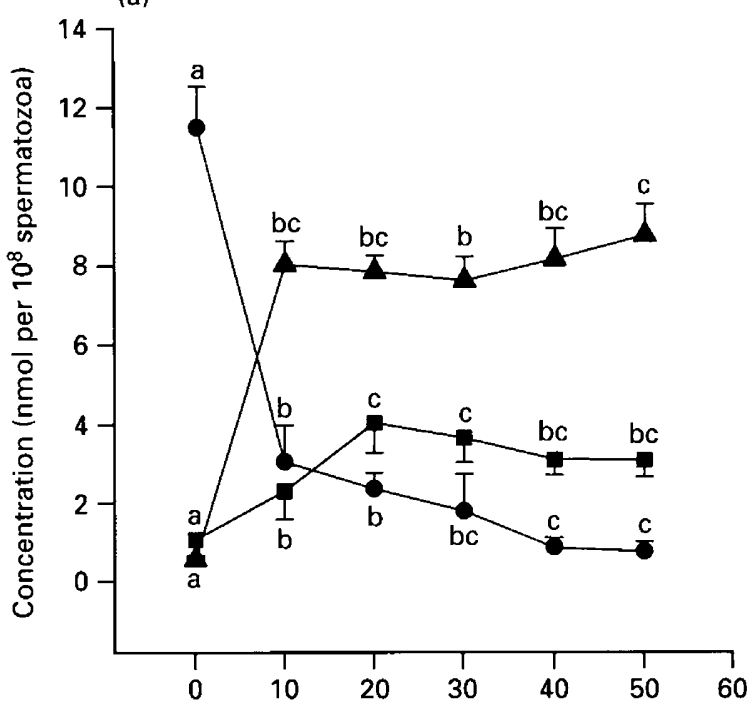

(b)

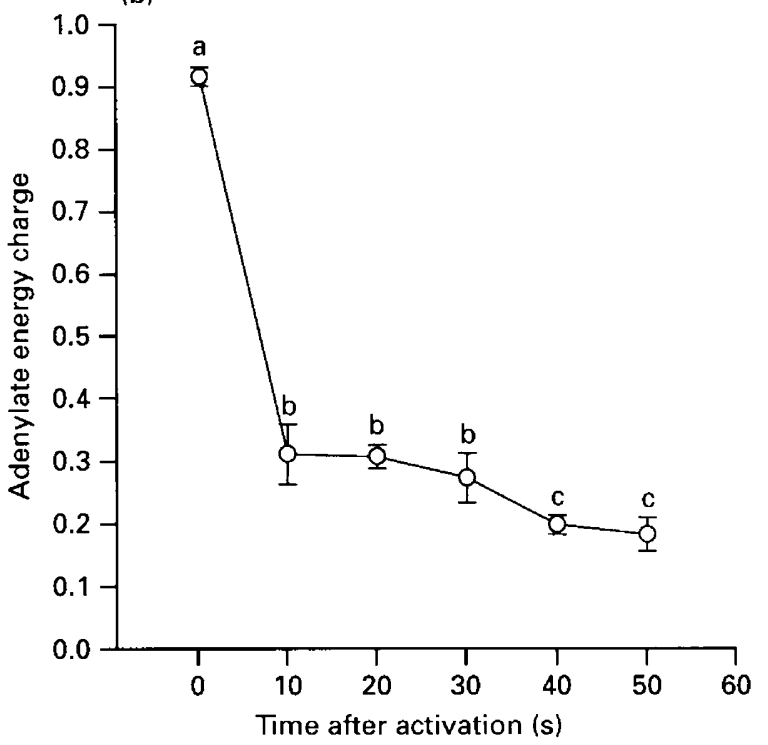

Fig. 8. Changes in the energetic metabolism of sea bass spermatozoa versus time after dilution in activating medium (AM1100). Significantly different values of intracellular contents of (a) adenylate nucleotides and (b) adenylate energy charge (AEC) versus time are indicated by different superscripts $(P<0.05)$. , ATP; $\boldsymbol{\square}, \mathrm{ADP} ; \boldsymbol{\Lambda}$, AMP.

4\%; Barnabé, 1976; turbot: $0.6-0.8 \%$; Suquet et al., 1994) and the high sperm concentration (sea bass: 10-40 $\times 10^{9}$ spermatozoa ml-1; Villani and Catena, 1991; turbot: $0.7-11 \times 10^{9}$ spermatozoa ml ${ }^{-1}$; Suquet et al., 1994). Therefore, in contrast with that of turbot, the reproductive strategy of sea bass may be to produce a large number of spermatozoa with lower individual motility performances and fertilizing capacities.

In sea bass as well as in sea urchin (Gibbons and Gibbons, 1980) and trout (Cosson et al., 1989; Boitano and Omoto, 1992), $\mathrm{Ca}^{2+}$ concentration plays a key role in the regulation of flagellar movement. In sea urchin spermatozoa, the intracellular concentration of $\mathrm{Ca}^{2+}$ was shown to govern the beat asymmetry which in turn is responsible for the curvature of tracks (Gibbons and Gibbons, 1980). The evolution of sea bass spermatozoa tracks from linear to tightly circular is reminiscent of that initially observed in sea urchin (Gibbons and Gibbons, 1980). The $\mathrm{Ca}^{2+}$ effects in sea bass spermatozoa were investigated by testing demembranated-reactivated sperm models at various $\mathrm{Ca}^{2+}$ concentrations combined with variations of other ions concentrations (ionic strength). The swimming behaviour of spermatozoa was sensitive to $\mathrm{Ca}^{2+}$ concentration as well as ionic strength (potassium acetate or $\mathrm{KCl}$ or $\mathrm{NaCl}$ ). Mostly an increase of $\mathrm{Ca}^{2+}$ decreases the track diameter which results from an increase in flagellar beat asymmetry. In trout, the activation of sperm movement is associated with a rise in intracellular free $\mathrm{Ca}^{2+}$ which results from the entry of extracellular $\mathrm{Ca}^{2+}$ (Cosson et al., 1989; Boitano and Omoto, 1992). Cosson et al. (1989) suggested that the increase of internal $\mathrm{Ca}^{2+}$ may be responsible for the appearance of asymmetric flagellar beating. Nevertheless, high concentrations of $\mathrm{Ca}^{2+}$ in the reactivation medium did not block wave generation in sea bass spermatozoa. Consequently, the cessation of wave generation observed in vivo at the end of the motility phase could not be due to a rise of $\mathrm{Ca}^{2+}$. In sea bass, $\mathrm{Ca}^{2+}$ combined with ionic strength effects leads to two consequences, that is, variations of track diameters and asymmetric beating similar to the $\mathrm{Ca}^{2+}$ effects on wave amplitude along the flagellum reflected by a dampening in the distal part. At the end of the swimming phase, native sea bass spermatozoa demonstrate wave dampening similar to demembranated cells. In ciona (Ciona intestinalis), increased ionic strength in the reactivation medium induced a reduction of bend angle and amplitude of propagated flagellar bends without change in the frequency of bend initiation, resulting from the decrease of metachronous component of sliding (Brokaw, 1993). $\mathrm{Ca}^{2+}$ and ionic strength effects observed in vitro explain the in vivo observations where wave parameters evolve rapidly after sea water activation. Transfer into sea water exposes sperm cells to a high osmolality which subsequently forces cells to react similarly to an osmometer. To readjust the osmolality, imbalanced water is expelled from the cell leading to two main consequences: (1) increase of solute concentration, including ionic strength will increase, and (2) an increase of intracellular $\mathrm{Ca}^{2+}$. When observed in vitro, both parameters, that is, ionic strength and $\mathrm{Ca}^{2+}$ concentration, mimic the changes in wave parameters appearing during the short in vivo motility phase.

The ATP content of sea bass spermatozoa (11.48 \pm $1.05 \mathrm{nmol}$ per $10^{8}$ spermatozoa) before activation was close to that reported for carp $\left(15.24 \pm 2.38 \mathrm{nmol}\right.$ per $10^{8}$ spermatozoa; Perchec et al., 1995), European catfish (Silurus glanis, 12-14 nmol per $10^{8}$ spermatozoa; Jeulin and Billard, 1995) or bull (12.9 nmol per $10^{8}$ spermatozoa; Newton and Rothschild, 1961). Higher concentrations were reported for turbot (26.0 \pm $3.8 \mathrm{nmol}$ per $10^{8}$ spermatozoa; Dreanno et al., 1997) and rat (100 nmol per $10^{8}$ spermatozoa; Jeulin and Billard, 1995). In sea bass, individual variations of the ATP content of immotile spermatozoa were low $(9 \%)$. After sperm activation, ATP concentrations dropped remarkably. At $10 \mathrm{~s}$ after activation, cells had already hydrolysed $74 \%$ of their initial ATP stores. In carp and European catfish, $60 \%$ and $70 \%$ of the ATP 

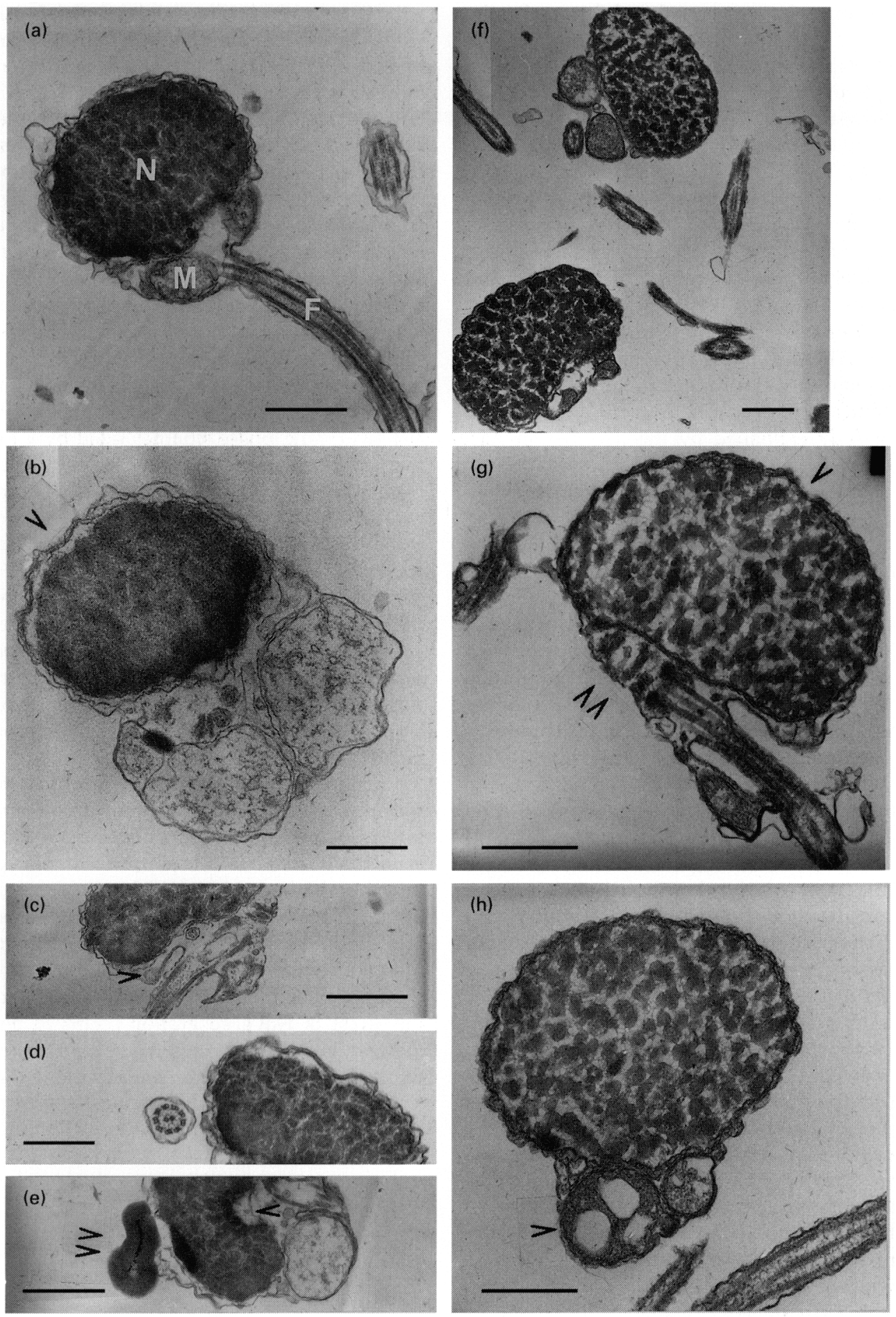

Fig. 9. Electron micrographs of sea bass spermatozoa before and after activation of motility. (a) Longitudinal section of native spermatozoon (F, flagellum; $M$, mitochondria; $N$, nucleus). (b) Head section of native spermatozoon; arrowhead indicates the cytoplasmic space. (c) Detail of the midpiece of native spermatozoon showing a densification of the membrane (arrowhead). (d) Section of the flagellum exhibiting the ' $9+2$ ' pattern. (e) Detail of the head of native spermatozoon; arrowheads indicate cellular residue. (f) General appearance of spermatozoa $40 \mathrm{~s}$ after activation. Note the heterogeneous aspect of the chromatin. (g) Head section of spermatozoon $40 \mathrm{~s}$ after activation; arrowhead indicates plasma membrane sticking to the nuclear envelope, double arrowheads show proximal and distal centrioles located at right angles to each other. (h) Head section of spermatozoon $40 \mathrm{~s}$ after activation, arrowhead indicates the shrinkage of the mitochondria and the greatly enlarged intracristal spaces. Scale bars represent $0.5 \mu \mathrm{m}$. 
content was used after longer periods of 2 and $1 \mathrm{~min}$, respectively.

The motility of spermatozoa depends on the dynein ATPases, which hydrolyse ATP to produce flagellar beating (Gibbons, 1968). In sea bass, the energy charge of non-motile spermatozoa is about 0.9 , meaning that $90 \%$ of the adenosine is in a high-energy form available for cellular function. Nevertheless, after the activation of motility, the AEC decreases abruptly, and becomes constant $20 \mathrm{~s}$ after activation, indicating that the amount of ATP hydrolysed by dynein ATPases is much higher than the amount of ATP produced by phosphorylative oxidation. Mitochondrial oxidative phosphorylation does not compensate sufficiently for the ATP utilized by the ATPases coupled to motility. This lack of efficiency may explain the relative lack of sperm motion in sea bass, trout and carp. Nevertheless, the cessation of movement is not fully explained by the decrease in ATP content. The internal molality of nucleotides was calculated assuming that the internal volume of the sea bass spermatozoon was similar to that of the trout spermatozoon ( $0.16 \mu \mathrm{l}$ per $10^{7}$ spermatozoa; Christen et al., 1987). At the beginning of the motile phase, the ATP concentration was $7 \mathrm{mmol} \mathrm{l}^{-1}$ and decreased to $0.6 \mathrm{mmol} \mathrm{l}^{-1}$ at the end of the swimming phase. Taking the $K_{\mathrm{m}}$ value of ATP for axonemal dyneins (trout: $0.20 \mathrm{mmol} \mathrm{l}^{-1}$; Cosson et al., 1995) into account, the final ATP concentration should be sufficient to sustain motility. At $30 \mathrm{~s}$ after activation, the ADP accumulated during the motility phase reached a concentration of $2.28 \mathrm{mmol}^{-1}$, while the ATP concentration was about $1.13 \mathrm{mmol} \mathrm{l}^{-1}$. Taking the $K_{1}$ of ADP (sea urchin: $0.27 \mathrm{mmol} \mathrm{l}^{-1}$, Penningroth and Peterson, 1986) into account, ADP concentrations may exhibit a competitive inhibition on the dynein ATPase. Omoto (1991) suggested that a high concentration of accumulated ADP contributes to the decrease in flagellar beat frequency. Therefore, high consumption of ATP and the accumulation of ADP after activation could explain the short distance covered by sea bass spermatozoa during the motile phase.

As indicated by the results of the present study, osmotic readjustment may regulate motility. Furthermore, osmotic damage to cellular structures may limit the duration of sperm movement. The sea bass spermatozoon is considered of a primitive type (Franzen, 1970) or as a simple anacrosomal aquasperm because of its rounded nucleus, reduced middle piece and typical ' $9+2$ ' axoneme (Jamieson, 1991). The chromatin of sea bass spermatozoa is granular and the existence of true protamine in the nucleus results in poor condensation of the chromatin (Saperas et al., 1993). After activation, there was a $32 \%$ increase in nucleus length and a $20 \%$ increase in width, despite spermatozoa being maintained in the hyperosmotic environment of the activation medium. These findings may represent the first step of chromatin decondensation after activation. During the insemination of medaka (Oryzias latipes) ova, nuclear chromatin decondenses and disperses in the apical region of the sperm head, while the nuclear envelop displays various stages of vesiculation (Iwamatsu and Ohta, 1978). In ayu (Plecoglossus altivelis), a swelling phenomenon has been reported in mitochondria for a wide range of osmotic pressure ranging from 100 to $600 \mathrm{mOsm} \mathrm{kg}^{-1}$ (Utsugi, 1993). In black porgy (Acanthopagrus schlegelli), black grouper (Epinephelus malabaricus) and
Atlantic croaker (Micropogonias undulatus) (Gwo, 1995), as well as in sea bass, the intracristal spaces of mitochondria are dilated after activation in sea water. The mitochondria of these four marine fish species shrink, which may explain the low mitochondrial activity during the motile period and the short duration of swimming of sea bass spermatozoa. In carp, the head of spermatozoon undergoes considerable swelling after dilution in fresh water, while the tip of flagellum exhibits marked coiling (Perchec et al., 1996). The formation of the coiled position slows down cell motion by superimposing dynamic constraints on normal flagellar movement (Perchec et al., 1996). Moreover, in trout, as well as in carp, alteration of the plasma membrane structure occurs (Billard, 1978; Marian et al., 1993, 1997).

When sperm motility was triggered by the dilution in an activating medium with an osmolality of $630 \mathrm{mOsm} \mathrm{kg}^{-1}$, the last swimming phase, characterized by a low flagellar beat frequency and low propulsive velocity, was prolonged. In carp, when motility was activated by dilution in an ionic medium (osmolality, $10 \mathrm{mOsm} \mathrm{kg}{ }^{-1}$ ) rather than distilled water (2 $\mathrm{min})$, the total duration of swimming of some spermatozoa reaches $10 \mathrm{~min}$ (Perchec et al., 1996). The smaller osmolality shock prolonged the duration of the movement but did not change the parameters of forward movement (velocity and flagellar beat frequency). Spermatozoa placed under marked osmotic pressure equilibrate the osmolality on both sides of the plasma membrane by exchange of water. Under low osmotic shock, the regulation of homeostasis is facilitated.

In conclusion, the brief duration of motility of sea bass spermatozoa is probably due to a combination of several factors. A large part of the energy required for sperm motility is obtained from ATP stores pre-accumulated in the testis, as mitochondrial oxidative phosphorylation during the motility phase alone is not able to compensate for the total ATP hydrolysis by ATPases coupled to movement. The cessation of the movement is explained, at least in part, by the lack of high energy phosphate compounds. Moreover, the arrest of wave generation seems to be induced by an increase in ionic strength. Wave patterns may depend on the intracellular calcium concentration. In addition, ultrastructural changes resulting from hyperosmotic shock may contribute to the shortening of the swimming phase.

The authors express their sincere thanks to F. Cosson for advice in mathematical and statistical analyses, P. Vallonne (IFREMER) for broodstock management and J. Faurillon (Muséum National $\mathrm{d}^{\prime}$ Histoire Naturelle) for typing this text. This research was supported by IFREMER, Muséum National d'Histoire Naturelle and CNRS (URM number 3).

\section{References}

Atkinson DE (1968) The energy charge of the adenylate pool as regulatory parameter: interaction with feedback modifiers Biochemistry $74030-4034$

Barnabé G (1976) Contribution à la connaissance de la biologie du loup Dicentrarchus labrax (L.) (Poisson Serranidae) pp 426. Thesis, University of Languedoc

Baynes SM, Scott AP and Dawson AP (1981) Rainbow trout, Salmo gairdnerii Richardson, spermatozoa: effect of cations and $\mathrm{pH}$ on motility Journal of Fish Biology 19 259-267 
Billard R (1978) Changes in structure and fertilizing ability of marine and freshwater fish spermatozoa diluted in media of various salinities Aquaculture 14 187-198

Billard R (1984) La conservation des gamètes et l'insémination artificielle chez le bar et la daurade. In L'Aquaculture du bar et des Sparidés pp 95-116 Eds G Barnabé and R Billard. INRA Publication, Paris

Billard R and Cosson MP (1989) Measurement of sperm motility in trout and carp. In Aquaculture a Biotechnology in Progress pp 499-503 Eds N de Pauw, E Jaspers, $\mathrm{H}$ Ackefors and N Wilkins. European Aquaculture Society, Bredene

Billard R and Cosson MP (1992) Some problems related to the assessment of sperm motility in freshwater fish Journal of Experimental Zoology 261 122-131

Billard R, Dupont J and Barnabé G (1977) Diminution de la motilité et de la durée de conservation du sperme de Dicentrarchus labrax L. (Poisson, Téléostéen) pendant la période de spermiation Aqquaculture 11 363-367

Billard R, Cosson J and Crim LW (1993) Motility of fresh and aged halibut sperm Aquatic Living Resources 6 67-75

Boitano S and Omoto CK (1992) Trout sperm swimming pattern and role of intracellular $\mathrm{Ca}^{2+}$ Cell Motility and Cytoskeleton 21 74-82

Brokaw CJ (1986) Sperm motility. In Methods in Cell Biology: Echinoderm Gametes and Embryo Vol. 27, pp 41-62 Ed. T Schroeder. Academic Press, New York

Brokaw CJ (1993) Microtubule sliding in reduced-amplitude bending waves of ciona sperm flagella: resolution of metachronous and synchronous sliding components of stable bending waves Cell Motility and Cytoskeleton 26 144-162

Chauvaud L, Cosson J, Suquet M and Billard R (1995) Sperm motility in turbot, Scophthalmus maximus: initiation of movement and changes of swimming characteristics Environmental Biology of Fishes 43 341-349

Christen R, Gatty JL and Billard R (1987) Trout sperm motility: the transient movement of trout sperm is related to changes in the concentration of ATP following the activation of the flagellar movement European Journal of Biochemistry $166667-671$

Cosson J, Billard R, Cibert C, Dreanno C, Linhart O and Suquet M (1997) Movements of fish sperm flagella studied by high speed videomicroscopy coupled to computer assisted image analysis Polskie Archiwum Hydrobiologii 44 103-113

Cosson MP, Billard R, Gatty JL and Christen R (1985) Rapid and quantitative assessment of trout spermatozoa using stroboscopy Aquaculture 46 71-75

Cosson MP, Billard $\mathbf{R}$ and Letellier $\mathrm{L}(1989)$ Rise of internal $\mathrm{Ca}^{2+}$ accompanies the initiation of trout sperm motility Cell Motility and Cytoskeleton 14 424-434

Cosson MP, Cosson J, André F and Billard R (1995) CAMP/ATP relationship in the activation of trout sperm motility: their interaction in membranedeprived models and in live spermatozoa Cell Motility and Cytoskeleton 31 159-176

Devauchelle N and Coves D (1988) The characteristics of sea bass (Dicentrarchus labrax) eggs: description, biochemical composition and hatching performances Aquatic Living Resources $1223-230$

Dreanno $C$, Suquet $M$, Quemener $L$, Cosson J, Fierville F, Normant $Y$ and Billard R (1997) Cryopreservation of turbot (Scophthalmus maximus) spermatozoa Theriogenology 48 589-603

Dreanno C, Suquet M, Fauvel C, Le Coz JR, Dorange G, Quemener L and Billard $\mathbf{R}$ The effect of ageing process on the quality of sea bass (Dicentrarchus labrax) semen Journal of Applied Ichthyology (in press)

Franzen A (1970) Phylogenetic aspects of the morphology of the spermatozoa and spermiogenesis. In Comparative Spermatology pp 29-46 Eds B Bacetti. Academic Press, New York

Gibbons IR (1968) Cilia and flagella of eukaryotes Journal of Cell Biology 91 107-124

Gibbons BH and Gibbons IR (1980) Calcium-induced quiescence in reactivated sea urchin sperm Journal of Cell Biology 84 13-27

Gwo JC (1995) Ultrastructural study of osmolality effect on spermatozoa of three marine teleosts Tissue Cell 27 491-497

Iwamatsu T and Ohta T (1978) Electron microscopic observation on sperm penetration and pronuclear formation in the fish egg Journal of Experimental Zoology 205 157-180

Jamieson GM (1991) Fish Evolution and Systematic: Evidence from Spermatozoa pp 319 Ed. GM Jamieson. Cambridge University Press, Cambridge

Jeulin C and Billard R (1995) L'énergétique du mouvement flagellaire des spermatozoides de vertébrés: des stratégies différentes selon que la fécondation est interne ou externe Comptes rendus de l'Académie de l'Agriculture de France 81 147-157
Lahnsteiner F and Patzner RA (1998) Sperm motility of the marine teleosts Boops boops, Diplodus sargus, Mullus barbatus and Trachurus mediterraneus. Journal of Fish Biology 52 726-742

Marian T, Krasznai Z, Balkay L, Balazs M, Emri M, Bene L and Tron L (1993) Hypo-osmotic shock induces an osmolality dependent permeabilisation and structural changes in the membrane of carp sperm Journal of Histochemistry and Cytochemistry 41 291-297

Marian T, Krasznai Z, Balkay L, Balazs M, Emri M and Tron L (1997) Role of extracellular and intracellular $\mathrm{pH}$ in carp sperm motility and modifications by hyperosmosis of regulation of the $\mathrm{Na}^{+} / \mathrm{H}^{+}$exchanger Cytometry 27 374-382

Morisawa M (1994) Cell signaling mechanism for sperm motility Zoological Science 11 647-662

Morisawa M and Suzuki K (1980) Osmolality and potassium ion: their role in initiation of sperm motility Science 210 1145-1147

Morisawa M and Morisawa S (1990) Acquisition and initiation of sperm motility. In Controls of Sperm Motility: Biological and Clinical Aspects pp 137-151 Ed. C Gagnon. CRC Press, Boston

Newton AA and Rothschild L (1961) Energy-rich phosphate compounds in bull semen: comparison of their metabolism with anaerobic heat production and impedance change frequency Proceedings of the Royal Society 155B 183

Oda S and Morisawa M (1993) Rises of intracellular $\mathrm{Ca}^{2+}$ and $\mathrm{pH}$ mediate the initiation of sperm motility by hyperosmolality in marine teleosts Cell Motility and Cytoskeleton 25 171-178

Omoto CK (1991) Mechanochemical coupling in cilia Internationnal Review of Cytology 131 255-292

Penningroth SM and Peterson DD (1986) Evidence for functional differences between two flagellar dynein ATPases Cell Motility and Cytoskeleton 6 586-594

Perchec G, Jeulin C, Cosson J, André F and Billard R (1995) Relationship between sperm ATP content and motility of carp spermatozoa Journal of Cell Science 108 747-753

Perchec G, Cosson MP, Cosson J, Jeulin C and Billard R (1996) Morphological and kinetic changes of carp (Cyprinus carpio) spermatozoa after initiation of motility in distilled water Cell Motility and Cytoskeleton 35 113-120

Robitaille PM, Munfort K and Brown G (1987) ${ }^{31} \mathrm{P}$ nuclear magnetic resonance study of trout spermatozoa at rest, after motility, and during short-term storage Biochemistry and Cell Biology 65 474-485

Saperas N, Ribes E, Buesa C, Garcia-Hegart F and Chiva M (1993) Differences in chromatin condensation during spermiogenesis in two species of fish with distinct protamines Journal of Experimental Zoology 265 185-194

Schlenk MK and Kahmann H (1938) Die chemische zusamennsetzung des spermaliquors und ihre physiologische bedeutung. Untersuchung am forellensperma Biochemical Zoology 295 283-301

Schoëvaert D, Krishnaswamy S, Couturier M and Marano F (1988) Ciliary beat and cell motility of Dunalillia: computer analysis of high speed microcinematography Biology of the Cell 62 229-240

Sorbera LA, Mylonas CC, Zanuy S, Carillo M and Zohar Y (1996) Sustained administration of GnRHa increases milt volume without altering sperm counts in the sea bass Journal of Experimental Zoology 276 361-368

Stoss J (1983) Fish gamete preservation and spermatozoa physiology. In Fish Physiology Vol. IXB, pp 305-340 Eds WS Hoar, DJ Randall and EM Donaldson. Academic Press, Orlando

Suquet M, Billard R, Cosson J, Dorange G, Chauvaud L, Mugnier C and Fauvel C (1994) Sperm features in turbot (Scophthalmus maximus): a comparison with other freshwater and marine fish species Aquatic Living Resources 7 283-294

Suquet M, Dreanno C, Dorange G, Normant Y, Quemener L, Gaignon JL and Billard R (1998) The ageing phenomenon of turbot spermatozoa: effects on morphology, motility and concentration, intracellular ATP content, fertilization and storage capacities Journal of Fish Biology 52 31-41

Utsugi K (1993) Motility and morphology of sperm of the Ayu, Plecoglossus altivelis, at different salinities Japan Journal of Ichthyology 40 273-278

Villani P and Catena C (1991) Gametes cryopreservation of male sea bass (Dicentrarchus labrax L.): solutions and methodologies Rivista Italiana Acquacoltura 26 217-226

Zohar Y, Billard R and Weil C (1984) La reproduction de la daurade (Sparus aurata) et du bar (Dicentrarchus labrax): connaissance du cycle sexuel et contrôle de la gamétogenèse et de la ponte. In L'Aquaculture du bar et des Sparidés pp 95-116 Eds G Barnabé and R Billard. INRA Publication, Paris 